\title{
Stroke among Siblings in a Biethnic Community
}

\author{
Lynda D. Lisabeth ${ }^{\mathrm{a}, \mathrm{b}} \quad$ Patricia A. Peyser ${ }^{\mathrm{a}} \quad$ Jeffrey C. Long ${ }^{\mathrm{c}} \quad$ Jennifer J. Majerisk ${ }^{\mathrm{b}}$ \\ Melinda A. Smith ${ }^{b}$ Lewis B. Morgenstern ${ }^{a}$ b \\ ${ }^{a}$ Department of Epidemiology, University of Michigan School of Public Health, ${ }^{b}$ Stroke Program, University of \\ Michigan Medical School, and ' Department of Human Genetics, University of Michigan, Ann Arbor, Mich., USA
}

Key Words

Stroke $\cdot$ Ethnicity $\cdot$ Familial aggregation • Genes

\begin{abstract}
Background: Mexican Americans (MAs) have an increased risk of stroke compared with non-Hispanic whites (NHWs), especially at younger ages. Little is known regarding patterns of familial aggregation of stroke and whether familial risk assessment might prove a potentially useful tool in assessing stroke risk in this population. This study's objective was to estimate the sibling recurrence risk ratio $\left(\lambda_{s}\right)$ for stroke and to compare this ratio between MAs and NHWs. Methods: Stroke and transient ischemic attack (TIA) cases $(n=181)$ between the ages of 45 and 64 years were identified by a population-based stroke study in a biethnic Texas community. $\lambda_{\mathrm{s}}$ was calculated overall and by ethnicity. Results: Siblings of ischemic stroke/TIA cases had a doubling in stroke risk compared to what would be expected based on national stroke prevalence estimates $\left(\lambda_{\mathrm{s}}=1.92 ; 95 \% \mathrm{Cl}\right.$ : 1.39-2.61). $\lambda_{\text {s }}$ was 2.0 (95\% Cl: 1.39-2.81) among MA stroke/TIA cases and 1.66 (95\% Cl: 0.82-3.10) among NHW stroke/TIA cases. Conclusion: The sibling recurrence risk for stroke was elevated in MA stroke/TIA cases suggesting that further ischemic stroke genetic studies across ethnicities may be warranted. In addition, a positive family history could prove a useful factor in the clinical setting for identifying MAs at increased stroke risk.

Copyright ๑ 2008 S. Karger AG, Basel
\end{abstract}

\section{Introduction}

Familial aggregation analyses hold promise in identifying individuals at high risk for atherosclerotic disease early in its course so that prevention efforts may be implemented. Ischemic stroke tends to aggregate in families, with a positive family history conferring a relative risk of stroke of a magnitude of 1.3-1.8 in epidemiologic studies $[1,2]$. Previous research regarding familial aggregation of stroke and the genetics of ischemic stroke have largely been limited to Caucasian populations. Recently, two genes for common forms of ischemic stroke have been identified in the Icelandic population [3, 4]. Replication of these findings in other populations has been somewhat inconsistent [5-8]. While there are several ongoing studies on the genetics of ischemic stroke, it is clear that additional studies will be needed. In particular, studies of minority populations with an increased risk of stroke are warranted. As an example, Mexican Americans (MAs) have an increased risk of stroke compared with non-Hispanic whites (NHWs) especially at younger ages [9]. To aid in the planning of such studies, it is of interest to understand how familial aggregation of stroke differs among ethnic groups. The sibling recurrence risk ratio $\left(\lambda_{s}\right)$ is a standard measure of familial aggregation. A greater risk of disease in siblings of affected individuals compared with the general population is consistent with the involvement of genes in the disease etiology. Additionally,

\section{KARGER \\ Fax +41613061234 \\ E-Mail karger@karger.ch}

www.karger.com (c) 2008 S. Karger AG, Basel

Accessible online at:

www.karger.com/ned

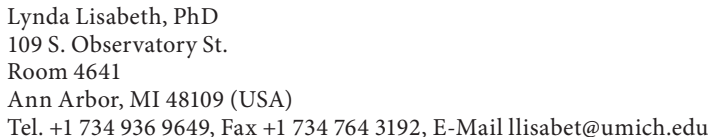


$\lambda_{s}$ is frequently used to estimate the power of planned genetic studies [10].

Measures of sibling recurrence risk may also shed light on the potential benefit of familial risk assessment. Familial risk assessment is a potentially important method for identifying individuals at risk and can influence appropriate screening and prevention strategies. While MAs have an increased risk of stroke compared with NHWs, little is known regarding patterns of familial aggregation of stroke in this population specifically and whether familial risk assessment might prove a useful tool in reducing the disproportionate stroke burden in this population. The aim of this pilot study was to estimate $\lambda_{s}$ using data from a biethnic stroke surveillance study conducted in Nueces County, Tex., USA, and from national stroke prevalence data and to compare $\lambda_{s}$ between two ethnic groups, MAs and NHWs.

\section{Materials and Methods}

The Brain Attack Surveillance in Corpus Christi (BASIC) project is a population-based stroke surveillance study conducted in Nueces County. Methods of the BASIC project have been previously reported [11]. The population size of the study county is roughly 300,000 , and $95 \%$ of the population resides within the city of Corpus Christi. NHWs comprise $38 \%$ of the population, and MAs comprise 56\%. Nueces County serves as the regional referral medical center for southeast Texas and is approximately 150 miles from Houston and San Antonio ensuring complete case capture for stroke.

Ischemic strokes and transient ischemic attacks (TIAs) were identified among individuals $\geq 45$ years seen at 1 of 7 area hospitals located within the Nueces County between June 2004 and June 2006. Cases not presenting to a hospital were identified by neurologists $(n=11)$ practicing in Nueces County. Cerebrovascular events were validated by board-certified neurologists based on published criteria and blinded to the subjects' ethnicity and age [12]. Stroke was defined as the acute onset (from minutes to hours) of a focal neurologic deficit specifically attributable to a cerebrovascular distribution that persists $>24 \mathrm{~h}$ and is not attributable to another disease process (seizure, brain tumor, hypoglycemia, metabolic encephalopathy or hysteria). A diagnosis of TIA was the same except that symptoms abated within $24 \mathrm{~h}$. Cases validated as intracerebral hemorrhage or subarachnoid hemorrhage were excluded. Because there is evidence to suggest that genetic influences for stroke may be more important at younger ages [13-15], the analysis was limited to probands with an age of onset $<65$ years.

\section{Family History of Stroke and Family Size Data}

A random sample of cases was asked to participate in an inperson interview regarding family history of stroke among firstdegree biologic relatives (parents, siblings, children) and asking for information on the number of biologic brothers and sisters. Per the BASIC study protocol, $75 \%$ of cases are randomized to the in-person interview in an attempt to interview 50\%. Response rates for interview are high at approximately $85 \%$ [16]. Cases unable to answer questions had a proxy interview in the presence of the case whenever possible. A previous analysis revealed high agreement (84-100\%) between patient/proxy interviews for 6 data elements (insurance, routine physician, hypertension, diabetes, smoking status, education and trust in doctors/nurses) [16]. Interviews were performed in English or Spanish.

Race-ethnicity was self-reported and collected as in the US census. MA ethnicity was defined as self-reported ethnicity 'of Hispanic origin' and race 'white' or 'refused'. Refused is included as it is common among this population to consider 'Hispanic' or 'Mexican American' a race. NHW was defined by a self-reported race of 'white' and ethnicity of 'not of Hispanic origin'. These categorizations should result in a relatively homogeneous group with respect to race-ethnicity as very few adult non-Hispanic Nueces County residents report multiple races $(<2 \%)$ [17].

The project was approved by the University of Michigan Institutional Review Board and each Nueces County hospital. All study subjects provided written informed consent.

\section{Stroke Prevalence Data}

Data on the prevalence of stroke in the general population was taken from the 2001 National Health Interview Survey (NHIS) [18]. Annually, a representative sample of US households is selected using a multistage cluster sample design (response rate $=74 \%$ ). Survey respondents self-report race and ethnicity using categories similar to the US census. Stroke prevalence data provided by gender and race-ethnicity was used for this analysis. Race-ethnicity categories of 'Hispanic' or 'Latino' and 'not Hispanic or Latino' and 'white' race were used to represent MAs and NHWs, respectively.

Stroke prevalence data for the ages of 44-65 years was used to correspond approximately to the age distribution of stroke cases. Age of siblings was added to the BASIC interview later, and therefore, this information was available for a subset of the cases interviewed as part of BASIC. Among this subset of 54 stroke cases $<65$ years of age, the median age of siblings was 52 years (interquartile range, IQR: 44.5-59). This data supports the use of the 44- to 65year age group in the NHIS data.

\section{Population Estimates of Stroke Risk Data}

Prevalence estimates of self-reported stroke risk factors (hypertension, diabetes, high cholesterol, smoking status) by gender and ethnicity among the general population were determined from an academic, professional random-digit telephone study of individuals in Nueces County conducted from July to September 1999 [19]. The estimates are included to provide a description of this population's cerebrovascular risk with respect to known stroke risk factors [16]. Race-ethnicity was obtained by self-report and collected similarly to the BASIC project. Only data for subjects $\geq 45$ years of age with no history of stroke are presented $(\mathrm{n}=339)$. This sample included $72 \mathrm{MA}$ men, $76 \mathrm{MA}$ women, 100 NHW men and 91 NHW women. The response rate for this telephone survey was $58 \%$.

\section{Statistical Analysis}

Median age and number of siblings were compared by ethnicity using Wilcoxon rank sum tests. Ethnic differences in stroke type and use of proxies were compared using $\chi^{2}$ tests. $\lambda_{s}$ was calculated as the ratio of observed number of strokes among siblings of stroke cases to expected number of strokes among siblings of 
stroke cases using national prevalence and family size information. Calculations were carried out within cross-classified categories of gender and ethnicity. For example, observed and expected counts were calculated for sisters of MA stroke cases who were $<65$ years of age using the corresponding stroke prevalence data from NHIS for MA females aged 44-65. Ninety-five percent confidence intervals (CIs) were calculated for $\lambda_{\mathrm{s}}$ using the exact Poisson method [20].

\section{Results}

Six hundred and one ischemic stroke/TIA cases were interviewed, with 566 (94.2\%) having complete family history data. Of the 566 cases, 181 were $<65$ years of age,

Table 1. Stroke prevalence in the general population 45-64 years of age by gender and ethnicity

\begin{tabular}{|c|c|c|c|c|c|c|}
\hline & \multicolumn{3}{|l|}{ MA } & \multicolumn{3}{|l|}{ NHW } \\
\hline & $\begin{array}{l}\text { number } \\
\text { with } \\
\text { stroke }\end{array}$ & $\begin{array}{l}\text { total } \\
\text { number }\end{array}$ & $\begin{array}{l}\text { preva- } \\
\text { lence } \\
\%\end{array}$ & $\begin{array}{l}\text { number } \\
\text { with } \\
\text { stroke }\end{array}$ & $\begin{array}{l}\text { total } \\
\text { number }\end{array}$ & $\begin{array}{l}\text { preva- } \\
\text { lence } \\
\%\end{array}$ \\
\hline Women & 35 & 2,707 & 1.29 & 500 & 24,671 & 2.03 \\
\hline Men & 87 & 2,484 & 3.50 & 413 & 23,368 & 1.77 \\
\hline
\end{tabular}

Estimates from 2001 National Health Interview Survey. with 130 (71.8\%) ischemic strokes and 51 (28.2\%) TIAs. The median age was 56 years (IQR: $51-61$ ) and was not different by ethnic group. Fifty-nine percent of cases were MA and $49.2 \%$ were female. Distribution of stroke type differed by ethnicity with ischemic stroke more common among MAs (78.5\%) compared with NHWs (62.3\%, p = $0.0163)$. The median number of siblings among MA cases was 5 (IQR: $3-7$ ) and 2 (IQR: 2-4) among NHW cases $(\mathrm{p}<0.001)$.

Nineteen percent (18.8\%) of interviews were conducted with proxies. There was a borderline significant association between ethnicity and proxy use (MAs 23.4\%, NHWs $12.2 \%, p=0.0578$ ). Within stroke type, proxy use did not differ by ethnicity, although sample sizes were small.

Stroke prevalence estimates for the general population are presented in table 1 with estimates of $\lambda_{\mathrm{s}}$ in this population by ethnicity and gender presented in table 2 . Siblings of stroke cases had a doubling in stroke prevalence compared with what would be expected based on national prevalence estimates $\left(\lambda_{\mathrm{s}}=1.92 ; 95 \%\right.$ CI: $\left.1.39-2.61\right)$. Among MA cases $<65$ years, $\lambda_{s}$ was greater than 1 for all of their siblings combined $\left(\lambda_{s}=2.0\right.$; 95\% CI: $\left.1.39-2.81\right)$ due to higher $\lambda_{s}$ in siblings of MA men $\left(\lambda_{s}=2.61 ; 95 \% \mathrm{CI}\right.$ : 1.64-3.99) versus siblings of MA women $\left(\lambda_{s}=1.47\right.$; $95 \%$ CI: 0.83-2.46). Among MA male cases, an elevated risk was observed among both their sisters and their brothers. Among NHW cases $<65$ years, only female cases had an

Table 2. Estimates of sibling recurrence risk ratio by gender and ethnicity among stroke/transient ischemic attack cases $<65$ years

\begin{tabular}{|c|c|c|c|c|c|c|c|}
\hline & \multicolumn{3}{|l|}{ MA } & \multicolumn{3}{|l|}{ NHW } & \multirow[t]{2}{*}{ Total } \\
\hline & women & men & total & women & men & total & \\
\hline Number of sisters & 145 & 149 & 294 & 44 & 66 & 110 & 404 \\
\hline Number of sisters with stroke & 4 & 5 & 9 & 2 & 0 & 2 & 11 \\
\hline Expected number of sisters with stroke & 1.87 & 1.93 & 3.80 & 0.89 & 1.34 & 2.23 & 6.03 \\
\hline Observed/expected & $\begin{array}{l}2.13 \\
(0.87-4.68)\end{array}$ & $\begin{array}{l}2.60 \\
(1.14-5.32)\end{array}$ & $\begin{array}{l}2.37 \\
(1.26-4.15)\end{array}$ & $\begin{array}{l}2.24 \\
(0.69-6.25)\end{array}$ & & $\begin{array}{l}0.90 \\
(0.28-2.50)\end{array}$ & $\begin{array}{l}1.82 \\
(1.03-3.05)\end{array}$ \\
\hline Number of brothers & 160 & 131 & 291 & 52 & 60 & 112 & 403 \\
\hline Number of brothers with stroke & 7 & 12 & 19 & 3 & 2 & 5 & 24 \\
\hline Expected number of brothers with stroke & 5.60 & 4.59 & 10.19 & 0.92 & 1.06 & 1.98 & 12.17 \\
\hline Observed/expected & $\begin{array}{l}1.25 \\
(0.62-2.33)\end{array}$ & $\begin{array}{l}2.62 \\
(1.51-4.29)\end{array}$ & $\begin{array}{l}1.86 \\
(1.20-2.79)\end{array}$ & $\begin{array}{l}3.26 \\
(1.19-7.86)\end{array}$ & $\begin{array}{l}1.89 \\
(0.58-5.25)\end{array}$ & $\begin{array}{l}2.53 \\
(1.11-5.17)\end{array}$ & $\begin{array}{l}1.97 \\
(1.33-2.84)\end{array}$ \\
\hline Number of siblings & 305 & 280 & 585 & 96 & 126 & 222 & 807 \\
\hline Number of siblings with stroke & 11 & 17 & 28 & 5 & 2 & 7 & 35 \\
\hline Observed/expected & $\begin{array}{l}1.47 \\
(0.83-2.46)\end{array}$ & $\begin{array}{l}2.61 \\
(1.64-3.99)\end{array}$ & $\begin{array}{l}2.00 \\
(1.39-2.81)\end{array}$ & $\begin{array}{l}2.76 \\
(1.22-5.66)\end{array}$ & $\begin{array}{l}0.83 \\
(0.26-2.32)\end{array}$ & $\begin{array}{l}1.66 \\
(0.82-3.10)\end{array}$ & $\begin{array}{l}1.92 \\
(1.39-2.61)\end{array}$ \\
\hline
\end{tabular}

Figures in parentheses are 95\% CIs. From BASIC, June 2004 to June $2006(\mathrm{n}=181)$. 
estimate of $\lambda_{s}$ significantly higher than $1\left(\lambda_{s}=2.76 ; 95 \%\right.$ CI: 1.22-5.66). $\lambda_{s}$ was statistically significantly higher than 1 in their brothers $\left(\lambda_{\mathrm{s}}=3.26 ; 95 \%\right.$ CI: 1.19-7.86) but not in their sisters $\left(\lambda_{\mathrm{s}}=2.24 ; 95 \%\right.$ CI: 0.69-6.25).

Prevalence estimates of stroke risk factors by gender and ethnicity in the general population of Nueces County are as follows: hypertension (MA men $54.2 \%$, MA women 39.5\%, NHW men 39.0\%, NHW women 34.1\%), diabetes (MA men 22.2\%, MA women 21.1\%, NHW men $12.0 \%$, NHW women $8.8 \%$ ), high cholesterol (MA men $34.7 \%$, MA women $43.4 \%$, NHW men $38.0 \%$, NHW women 35.2\%), and current smoker (MA men 26.4\%, MA women $19.7 \%$, NHW men $21.0 \%$, NHW women $22.0 \%$ ).

\section{Discussion}

In this community, $\lambda_{s}$ was approximately 2 among siblings of stroke/TIA cases $<65$ years. A significantly elevated risk among all siblings combined was observed among MA cases only. The finding of elevated sibling risk among MA stroke/TIA cases compared to expectations from the general population is new and provides an indicator of those at increased risk for stroke. Elevated sibling risk in MA cases in combination with increased sibling risk in brothers of NHW cases, and previous observations by others of increased sibling risk in a predominantly NHW population [13], suggest a potential genetic component to ischemic stroke in both ethnic groups.

Alternative plausible explanations for familial aggregation include shared sibling environments such as diet, physical activity and smoking habits. Hypertension and diabetes, which cluster in families and have genetic components, could also contribute to the observed familial aggregation of stroke and elevated risk among siblings of MAs. MAs in this community have a higher prevalence of diabetes compared with NHWs [16]. This higher prevalence of diabetes likely contributes to the higher stroke risk. The increased risk for stroke among MAs might be an outcome of a genetic predisposition to diabetes, or a higher prevalence of diabetes might make any stroke predisposing gene more penetrant in MAs. More research is required to identify specific genes, shared environments as well as gene-gene and gene-environment interactions, which increase the susceptibility to stroke in each ethnic group.

Interestingly, among MAs, the sibling recurrence risk ratio among both sisters and brothers of male cases was statistically significant while among NHWs, only the sibling recurrence risk ratio among brothers of female cases was significant. The reasons for these ethnic and genderspecific findings are unknown. Small numbers of affected siblings may have played a role although sex-specific differences have been noted with regard to stroke outcome [21-23], stroke subtype [24] and stroke risk factors $[22,25]$. Sex-specific differences with regard to the relationship of family history and coronary heart disease have also been noted [26]. Further study is needed to replicate possible gender and ethnic group differences in sibling recurrence risk as well as to identify underlying etiologic factors.

Previous research has started with estimates of familial aggregation to estimate sample size for stroke genetics research using various designs [13]. Study designs to identify stroke risk genes will require several hundred affected sib pairs [13]. Such studies may be more feasible in MAs given the higher sibling recurrence risk, larger families and higher likelihood of living siblings with stroke [27], although the ethnic diversity must be carefully considered when planning such a study. In addition, our work in this community suggests a willingness to participate in future stroke genetic studies in MAs [27]. Others have also found positive attitudes towards genetic studies among Hispanics potentially enhancing participation in future studies [28].

Limitations of this study warrant discussion. Sample size for this pilot study was small; however, the population is unique in that it is composed of over $50 \%$ MAs, a minority population with an increased risk of stroke at younger ages. Measurement error, including case ascertainment bias and misreporting of family history, are likely to occur in studies such as ours. With regard to case ascertainment, we have previously demonstrated that our method of combined active and passive surveillance is highly sensitive and superior to passive surveillance alone [29]. Further, we have reported no ethnic differences in the percentage of cases ascertained from out-of-hospital sources and no ethnic differences in access to care in this population $[9,16]$. Given our methods, we could not capture cases who did not present for medical attention. If presentation to medical attention differs by ethnicity and/or gender, such differences would bias our findings. It is possible that stroke/ TIA cases misreported stroke among siblings. Both underand overreporting were possible. The degree to which this misreporting may have occurred or how it may differ by ethnicity and/or gender are not known.

Our findings are limited only to siblings of cases with stroke onset between the ages of 45 and 64 . Cases below the age of 45 are likely to have young siblings who have not yet reached an age when they can contribute any in- 
formation to familial aggregation of stroke. For that reason we did not include any cases under the age of 45 .

Estimates of the prevalence of stroke were taken from a national survey versus a formal control population potentially introducing some bias. Results should be confirmed in additional epidemiologic studies with a control sample, if possible. Data from the national survey included all Hispanic subgroups as data was not available specifically for MAs broken down by age and gender. However, stroke prevalence did not differ among MAs (1.6\%) and all Hispanics (1.7\%).

Ischemic stroke subtype was unknown among cases, and stroke type was unknown among siblings. Stroke is a heterogeneous disorder and studies suggest that a familial component to stroke may be present in certain ischemic stroke subtypes $[14,15]$. We have previously demonstrated that there is no difference in the distribution of ischemic stroke subtype by ethnicity suggesting that this factor does not confound the observed association [30]. Age at stroke onset among siblings was not known for the entire sample of those interviewed as part of BASIC either as this data element was not added until a later point in time. Previous research has shown that estimates of sibling recurrence may be higher among younger siblings with strokes [13].

Lastly, it is important to consider the limitations of the measure of familial aggregation used here $\left(\lambda_{s}\right)$, as reviewed by Ashley-Koch [31]. The denominator is the prevalence in the population. Thus, when the prevalence in the population is high, a lower $\lambda_{s}$ should not necessarily be interpreted to suggest that the role of genes is weak. For example, atopy and prostate cancer, both relatively common traits, have an estimate of $\lambda_{s}$ similar to those reported here [32]. Estimates of $\lambda_{s}$ are population specific, and estimates higher than 1.0 could result from a common familial environment rather than shared genes.

\section{Conclusion}

All of the factors contributing to the increased risk of stroke at younger ages among MAs compared with NHWs have not yet been identified. While differences in traditional stroke risk factor profiles and socioeconomic status exist between the two ethnic groups, these factors are not likely to explain the large differences in disease risk. This first report of elevated sibling risk among MAs, along with the younger age of onset of stroke in MAs, suggests a possible genetic component to stroke in this ethnic group specifically and that stroke genetics research would be feasible in this population. Larger family size among MAs, as well as a willingness to participate in genetic studies, is a logistic advantage for the conduct of future stroke genetics studies. The role of genes in stroke may explain some of the ethnic differences in stroke risk, and this hypothesis should be explored in future studies. In addition, when the results regarding familial aggregation of stroke in MAs are replicated, a positive family history could prove a useful and easily obtainable factor in the clinical setting for identifying those individuals in this population at increased risk. Familial risk assessment has been shown to provide additional discriminatory ability over traditional risk factors in predicting early onset coronary heart disease [33] but such predictive models for stroke have yet to be developed.

\section{Acknowledgements}

This study was funded by K23 NS050161 and NIH RO1 NS38916.
References

\footnotetext{
1 Flossmann E, Schulz UG, Rothwell PM: Systematic review of methods and results of studies of the genetic epidemiology of ischemic stroke. Stroke 2004;35:212-227.

- 2 Kondo T, Toyoshima H, Tsuzuki Y, Hori Y, Yatsuya H, Tamakoshi K, Tamakoshi A, Ohno Y: Familial aggregation and coaggregation of history of hypertension and stroke. J Hum Hypertens 2005;19:119-125.
}

- 3 Helgadottir A, Manolescu A, Thorleifsson G, Gretarsdottir S, Jonsdottir H, Thorsteinsdottir U, Samani NJ, Gudmundsson G, Grant SF, Thorgeirsson G, Sveinbjornsdottir S, Valdimarsson EM, Matthiasson SE, Johannsson $\mathrm{H}$, Gudmundsdottir O, Gurney ME, Sainz J, Thorhallsdottir M, Andresdottir M, Frigge ML, Topol EJ, Kong A, Gudnason V, Hakonarson H, Gulcher JR, Stefansson $\mathrm{K}$ : The gene encoding 5-lipoxygenase activating protein confers risk of myocardial infarction and stroke. Nat Genet 2004;36: 233-239. 
-4 Gretarsdottir S, Sveinbjornsdottir S, Jonsson $\mathrm{HH}$, Jakobsson F, Einarsdottir E, Agnarsson U, Shkolny D, Einarsson G, Gudjonsdottir $\mathrm{HM}$, Valdimarsson EM, Einarsson $\mathrm{OB}$, Thorgeirsson G, Hadzic R, Jonsdottir S, Reynisdottir ST, Bjarnadottir SM, Gudmundsdottir T, Gudlaugsdottir GJ, Gill R, Lindpaintner K, Sainz J, Hannesson $\mathrm{HH}$, Sigurdsson GT, Frigge ML, Kong A, Gudnason V, Stefansson K, Gulcher JR: Localization of a susceptibility gene for common forms of stroke to $5 \mathrm{q} 12$. Am J Hum Genet 2002;70:593-603.

5 Saleheen D, Bukhari S, Haider SR, Nazir A, Khanum S, Shafqat S, Anis MK, Frossard P: Association of phosphodiesterase $4 \mathrm{~d}$ gene with ischemic stroke in a Pakistani population. Stroke 2005;36:2275-2277.

6 Nakayama T, Asai S, Sato N, Soma M: Genotype and haplotype association study of the strk1 region on 5q12 among Japanese: a casecontrol study. Stroke 2006;37:69-76.

$>7$ Kuhlenbaumer G, Berger K, Huge A, Lange E, Kessler C, John U, Funke H, Nabavi DG, Stogbauer F, Ringelstein EB, Stoll M: Evaluation of single nucleotide polymorphisms in the phosphodiesterase $4 \mathrm{~d}$ gene (pde4d) and their association with ischaemic stroke in a large German cohort. J Neurol Neurosurg Psychiatry 2006;77:521-524.

$\checkmark$ Brophy VH, Ro SK, Rhees BK, Lui LY, Lee JM, Umblas N, Bentley LG, Li J, Cheng S, Browner WS, Erlich HA: Association of phosphodiesterase $4 \mathrm{~d}$ polymorphisms with ischemic stroke in a US population stratified by hypertension status. Stroke 2006;37: 1385-1390.

$\checkmark 9$ Morgenstern LB, Smith MA, Lisabeth LD, Risser JM, Uchino K, Garcia N, Longwell PJ, McFarling DA, Akuwumi O, Al-Wabil A, AlSenani F, Brown DL, Moye LA: Excess stroke in Mexican Americans compared with nonHispanic whites: the Brain Attack Surveillance in Corpus Christi project. Am J Epidemiol 2004;160:376-383.

$>10$ Risch N: Linkage strategies for genetically complex traits. I. Multilocus models. Am J Hum Genet 1990;46:222-228.

-11 Smith MA, Risser JM, Moye LA, Garcia N, Akiwumi O, Uchino K, Morgenstern LB: Designing multi-ethnic stroke studies: the Brain Attack Surveillance in Corpus Christi (BASIC) project. Ethn Dis 2004;14:520-526.
12 Asplund K, Tuomilehto J, Stegmayr B, Wester PO, Tunstall-Pedoe H: Diagnostic criteria and quality control of the registration of stroke events in the MONICA project. Acta Med Scand 1988;728(suppl):26-39.

13 Hassan A, Sham PC, Markus HS: Planning genetic studies in human stroke: sample size estimates based on family history data. Neurology 2002;58:1483-1488.

14 Schulz UG, Flossmann E, Rothwell PM: Heritability of ischemic stroke in relation to age, vascular risk factors, and subtypes of incident stroke in population-based studies. Stroke 2004;35:819-824.

15 Jood K, Ladenvall C, Rosengren A, Blomstrand C, Jern C: Family history in ischemic stroke before 70 years of age: the Sahlgrenska Academy Study on ischemic stroke. Stroke 2005;36:1383-1387.

16 Smith MA, Risser JM, Lisabeth LD, Moye LA, Morgenstern LB: Access to care, acculturation, and risk factors for stroke in Mexican Americans: the Brain Attack Surveillance in Corpus Christi (BASIC) project. Stroke 2003;34:2671-2675.

172000 US Census. http://factfinder.Census. Gov/home/en/datanotes/expsflu.htm (accessed January 16, 2008).

18 Lucas JW, Schiller JS, Benson V: Summary health statistics for US adults: National Health Interview Survey, 2001. National Center for Health Statistics. Vital Health Stat 2004; 10:218.

19 Morgenstern LB, Steffen-Batey L, Smith MA, Moye LA: Barriers to acute stroke therapy and stroke prevention in Mexican Americans. Stroke 2001;32:1360-1364.

20 Ulm K: A simple method to calculate the confidence interval of a standardized mortality ratio. Am J Epidemiol 1990;131:373375.

21 Glader EL, Stegmayr B, Norrving B, Terent A, Hulter-Asberg K, Wester PO, Asplund K: Sex differences in management and outcome after stroke: a Swedish national perspective. Stroke 2003;34:1970-1975.

22 Di Carlo A, Lamassa M, Baldereschi M, Pracucci G, Basile AM, Wolfe CD, Giroud M, Rudd A, Ghetti A, Inzitari D: Sex differences in the clinical presentation, resource use, and 3-month outcome of acute stroke in Europe: data from a multicenter multinational hospital-based registry. Stroke 2003;34: 1114-1119.
23 Kapral MK, Fang J, Hill MD, Silver F, Richards J, Jaigobin C, Cheung AM: Sex differences in stroke care and outcomes: results from the registry of the Canadian stroke network. Stroke 2005;36:809-814.

24 Roquer J, Campello AR, Gomis M: Sex differences in first-ever acute stroke. Stroke 2003;34:1581-1585.

25 Holroyd-Leduc JM, Kapral MK, Austin PC, Tu JV: Sex differences and similarities in the management and outcome of stroke patients. Stroke 2000;31:1833-1837.

26 Scheuner MT, Whitworth WC, McGruder $\mathrm{H}$, Yoon PW, Khoury MJ: Expanding the definition of a positive family history for early-onset coronary heart disease. Genet Med 2006;8:491-501.

27 Lisabeth LD, Kardia SL, Smith MA, Fornage M, Morgenstern LB: Family history of stroke among Mexican-American and non-Hispanic white patients with stroke and TIA: implications for the feasibility and design of stroke genetics research. Neuroepidemiology 2005;24:96-102.

28 Catz DS, Green NS, Tobin JN, Lloyd-Puryear MA, Kyler P, Umemoto A, Cernoch J, Brown $\mathrm{R}$, Wolman F: Attitudes about genetics in underserved, culturally diverse populations. Community Genet 2005;8:161-172.

29 Piriyawat P, Smajsova M, Smith MA, Pallegar S, Al-Wabil A, Garcia NM, Risser JM, Moye LA, Morgenstern LB: Comparison of active and passive surveillance for cerebrovascular disease: the Brain Attack Surveillance in Corpus Christi (BASIC) project. Am J Epidemiol 2002;156:1062-1069.

-30 Uchino K, Risser JM, Smith MA, Moye LA, Morgenstern LB: Ischemic stroke subtypes among Mexican Americans and non-Hispanic whites: the BASIC project. Neurology 2004;63:574-576.

31 Ashley-Koch A: Determining genetic component of a disease; in Haines J, PericakVance M (eds): Genetic Analysis of Complex Diseases. Hoboken, Wiley-Liss, 2006, pp 105-106.

32 Altmuller J, Palmer LJ, Fischer G, Scherb H, Wjst M: Genomewide scans of complex human diseases: true linkage is hard to find. Am J Hum Genet 2001;69:936-950.

33 Scheuner MT, Whitworth WC, McGruder H, Yoon PW, Khoury MJ: Familial risk assessment for early-onset coronary heart disease. Genet Med 2006;8:525-531. 